\title{
Dialysis of isolated low density lipoprotein induces a loss of lipophilic antioxidants and increases the susceptibility to oxidation in vitro
}

\author{
Leo M. Scheek ${ }^{\mathrm{a}}$, Sheila A. Wiseman ${ }^{\mathrm{b}}$, Lilian B.M. Tijburg ${ }^{\mathrm{b}}$, Arie van Tol ${ }^{* a}$ \\ a Department of Biochemistry, Cardiovascular Research Institute (COEUR), Erasmus University, P.O. Box 1738, \\ 3000 DR Rotterdam, The Netherlands \\ b Unilever Research Laboratory, Vlaardingen, The Netherlands
}

Received 20 December 1994; accepted 23 February 1995

\begin{abstract}
We determined the effects of different dialysis conditions on the antioxidant content, duration of the lag phase and oxidation rate of LDL. Dialysis for $22 \mathrm{~h}$ resulted in a $56 \%-66 \%$ reduction in the concentrations of $\beta$-carotene, lycopene and $\alpha$-tocopherol. The lag phase of copper-induced oxidation of freshly isolated LDL was considerably longer than that of LDL dialysed for 22 or $44 \mathrm{~h}$. Our data show that dialysis may result in LDL preparations with antioxidant compositions that are not truly representative of freshly isolated lipoproteins.
\end{abstract}

Keywords: Anti-oxidants; Atherosclerosis; Dialysis; Low-density lipoprotein; Oxidation

\section{Introduction}

Several lines of evidence, from both in vitro and in vivo studies, suggest that oxidative modification of low density lipoprotein (LDL) may contribute to atherosclerosis [1-4]. A number of assays monitoring the oxidative susceptibility of the particle have been developed to evaluate the atherogenic potential of LDL [5-7]. Most often the LDL oxidation is initiated by incubating with cultured cells or with transition metal ions as pro-oxidants [5]. Esterbauer et al. [8] developed a method to assess the susceptibility of LDL to copper-mediated oxidation in vitro by continuous monitoring of the formation of conjugated dienes. The mechanistic aspects of this method were investigated recently $[9,10]$. The in vitro assay of conjugated diene formation is widely used to estimate the resistance of LDL to oxidation (e.g. $[12-14])$. This implies that the isolated $\mathrm{LDL}$

Abbreviations: LDL, low density lipoprotein; LPO, lipoperoxides; MDA, malondialdehyde; PBS, phosphate-buffered saline; TAG, triacylglycerol.

* Corresponding author. Tel.: + 31104087 321; Fax: + 31104360615 . 
should be representative of the circulating LDL particles in vivo.

Unfortunately, ultracentrifugation, the most widely used procedure for LDL isolation, is timeconsuming and preservatives like EDTA are regularly included in the high-salt solutions to limit oxidation. Isolated LDL are often extensively dialysed in order to remove these compounds prior to the oxidation assay. In this study we examined the effects of this dialysis step on the concentration of lipophilic antioxidants in LDL and on the parameters of the diene formation during oxidation of $\mathrm{LDL}$ in the presence of $\mathrm{Cu}^{2+}$.

\section{Methods}

\subsection{Subjects}

Nine healthy volunteers (6 males, 3 females) participated in the study after informed consent. Ages ranged from 25 to 50 years. The average plasma total cholesterol level was $5.4 \mathrm{mmol} / \mathrm{l}$ (range 4.2-5.3 in females and 4.4-6.6 in males). These and other characteristics of the study subjects are given in Table 1.

\subsection{Lipoprotein isolation, preparation and oxidation}

Blood samples were obtained, after an overnight fast, in EDTA-containing tubes. Plasma was prepared by centrifugation at $2000 \times g$ for $15 \mathrm{~min}$ at $4^{\circ} \mathrm{C}$. The plasma samples were divided into two identical aliquots and lipoproteins were separated by density gradient ultracentrifugation [15], using a Beckman SW40 or SW41 rotor and ultraclear centrifuge tubes. After ultracentrifugation, the LDL fractions $(d=1.019-1.063 \mathrm{~g} / \mathrm{ml})$ were collected by tube slicing. A part of the freshly isolated LDL in $0.1 \mathrm{mM}$ EDTA was immediately used for a conjugated diene formation assay [14]. Another part was stored immediately at $-80^{\circ} \mathrm{C}$ under nitrogen until analysis of antioxidants. LDL isolated in $1.0 \mathrm{mM}$ EDTA were dialysed against $0.01 \mathrm{mM}$ EDTA according to Kleinveld et al. [10].

Three different dialysis methods were used, varying in time and/or EDTA concentration. In all dialysis procedures $2 \mathrm{ml} \mathrm{LDL}$ samples were dialysed at $4^{\circ} \mathrm{C}$ in the dark against a total volume of 31 of $0.01 \mathrm{M}$ phosphate-buffered saline (PBS,
$\mathrm{pH}$ 7.4). All dialysis solutions were degassed and purged with nitrogen prior to use and during dialysis. In method A, LDL was dialysed for $22 \mathrm{~h}$ against PBS containing $0.01 \mathrm{mM}$ EDTA. In methods $B$ and $C, L D L$ were dialysed for $44 \mathrm{~h}$ against PBS with $0.01 \mathrm{mM}$ EDTA (method B) or without EDTA (method C). Immediately after dialysis the protein content of LDL was determined using bovine albumin as the standard [16], and the LDL samples were stored at $-80^{\circ} \mathrm{C}$, under nitrogen, until antioxidant measurement.

The formation of conjugated dienes during copper-mediated oxidation was continuously monitored at $234 \mathrm{~nm}$ in a Hitachi U $2000 \mathrm{UV} / \mathrm{VIS}$ spectrophotometer. Before the start of the oxidation experiments using dialysed LDL, samples were diluted with PBS to give a final concentration in the assay cuvette of $50 \mu \mathrm{g} / \mathrm{ml} \mathrm{LDL}$ protein and $1 \mu \mathrm{M}$ EDTA. The incubation mixture was brought to $30^{\circ} \mathrm{C}$ and $\mathrm{CuCl}_{2}$ was added to a final concentration of $5 \mu \mathrm{M}$ to initiate oxidation. The absorbance at $234 \mathrm{~nm}$ was monitored at $2 \mathrm{~min}$ intervals and the lag phase before conjugated diene formation occurred, as well as the maximum rate of oxidation and the maximal amount of conjugated dienes, was calculated from the oxidation profile [8]. When dialysis was omitted, LDL samples were diluted with $1.18 \mathrm{M} \mathrm{NaCl}$ containing $0.1 \mathrm{mM}$ EDTA, immediately after lipoprotein isolation. This ensured that the EDTA concentration was equal in all samples. $\mathrm{CuCl}_{2}$-mediated oxidation of undialysed LDL was carried out according to Princen et al. [14]. Briefly, $50 \mu \mathrm{g}$ of LDL protein was incubated at $30^{\circ} \mathrm{C}$ in a total volume of $1.0 \mathrm{ml} \mathrm{PBS}$ containing $50 \mu \mathrm{M} \mathrm{CuCl}_{2}$

Table 1

Characteristics of subjects

\begin{tabular}{lcc}
\hline & Mean \pm S.E.M. & Range \\
\hline Age (years) & $37.8 \pm 2.7$ & $25-50$ \\
BMI (kg/m $\left.{ }^{2}\right)$ & $22.1 \pm 0.8$ & $18.9-25.0$ \\
Plasma cholesterol (mM) & $5.42 \pm 0.82$ & $4.14-6.64$ \\
Plasma TAG (mM) & $1.08 \pm 0.28$ & $0.71-1.50$ \\
$\beta$-carotene (mg/l) & $0.33 \pm 0.13$ & $0.11-0.57$ \\
Lycopene (mg/l) & $0.24 \pm 0.12$ & $0.09-0.52$ \\
$\alpha$-tocopherol (mg/l) & $11.21 \pm 2.23$ & $8.34-14.80$
\end{tabular}

Data represent the mean of 9 individuals. BMI, body mass index; TAG, triacylglycerol. 
Table 2

Effect of dialysis on lipid-soluble antioxidants in LDL ( $\mu \mathrm{g}$ per mg LDL protein)

\begin{tabular}{lllll}
\hline & No dialysis & $22 \mathrm{~h}+$ EDTA & $44 \mathrm{~h}+$ EDTA & $44 \mathrm{~h}-\mathrm{EDTA}$ \\
\hline$\alpha$-tocopherol & $6.49+0.50^{\mathrm{a}}$ & $2.19 \pm 0.31$ & $3.00 \pm 0.31$ & $2.46 \pm 0.31$ \\
$\beta$-carotene & $0.36 \pm 0.04^{\mathrm{a}}$ & $0.16 \pm 0.04$ & $0.19 \pm 0.02$ & $0.13 \pm 0.03$ \\
Lycopene & $0.26 \pm 0.05^{\mathrm{a}}$ & $0.09 \pm 0.02$ & $0.12 \pm 0.03$ & $0.04 \pm 0.01$ \\
\hline
\end{tabular}

Data represent the mean \pm S.E.M. $(n=9)$.

asignificantly different from dialysed $\mathrm{LDL}, P<0.001$.

and conjugated diene formation was monitored at $234 \mathrm{~nm}$. The final EDTA concentration was 25 $\mu \mathrm{M}$.

\subsection{Analytical procedures}

The concentrations of $\beta$-carotene, lycopene and $\alpha$-tocopherol were determined in plasma and LDL as follows. LDL or plasma samples were extracted with $\mathrm{n}$-heptane containing $\delta$-tocopherol and ethyl- $\beta$-apo- $8^{\prime}$-carotenoate as internal standards. Lipid soluble antioxidants were determined by HPLC using an ET 200/8/4 nucleosil 5CN column $(250 \times 4 \mathrm{~mm}$, Mackery and Nagel $)$ and n-heptane-chloroform-2-propanol (100:1.5:0.15, $\mathrm{v} / \mathrm{v}$ ) as the mobile phase. The eluent was monitored with a UV/VIS detector set at $292 \mathrm{~nm}$ ( $\alpha$-tocopherol), $298 \mathrm{~nm}(\delta$-tocopherol) and 450 $\mathrm{nm}$ (carotenoids).

Total cholesterol and triacylglycerol in plasma and lipoprotein fractions were measured by standard enzymatic procedures (Boehringer, Mannheim, Germany) on a Cobas Mira S analyzer. Malondialdehyde (MDA) in LDL was determined by HPLC analysis after complexation with diethyl barbituric acid essentially as described by Wong et al. [17]. Lipoperoxides in LDL were measured with a iodometric assay [18].

\subsection{Statistical analysis}

Results are expressed as the mean \pm S.E.M. $(n=9)$. Statistical analysis was performed with the SAS statistical package. Data were analysed by one way ANOVA. Multiple comparisons between means were carried out using the Tukey test.

\section{Results and discussion}

In the present study we examined the effect of dialysis on the antioxidant content of LDL and on the susceptibility of LDL to copper-initiated oxidation. The data shown in Table 2 clearly indicate that dialysis of LDL resulted in a significant loss of $\alpha$-tocopherol, the major lipophilic antioxidant in LDL. After $22 \mathrm{~h}$ of dialysis, in the presence of 0.01 mM EDTA, the concentration of $\alpha$-tocopherol was decreased by approximately $66 \%$. Prolonged dialysis for up to $44 \mathrm{~h}$, in either the presence or absence of EDTA, did not further decrease LDL $\alpha$-tocopherol levels. Analysis of $\alpha$-tocopherol in all lipoprotein fractions gave a recovery of approximately $100 \%$ (not shown). The loss of $\beta$-carotene and lycopene from the LDL particle was comparable to that of $\alpha$-tocopherol (Table 2).

It was reported previously that, in LDL subjected to copper-mediated oxidation, depletion of lipophilic antioxidants precedes the propagation phase of the oxidation of polyunsaturated fatty acids [9]. This implies that the dialysis-induced loss of fat-soluble antioxidants may significantly affect the lag phase of oxidised LDL. To allow direct measurement of the oxidation of freshly isolated LDL in the presence of EDTA $(25 \mu \mathrm{M})$, we determined the optimal copper concentration in the assay mixture. The optimum was found to be $50 \mu \mathrm{M}$, close to the $40 \mu \mathrm{M}$ reported by Princen et al. [14].

The optimal $\mathrm{CuCl}_{2}$ concentration for the oxidation of dialysed LDL particles in the presence of 1 $\mu \mathrm{M}$ EDTA at protein concentration of $50 \mu \mathrm{g} / \mathrm{ml}$ was determined to be $5 \mu \mathrm{M}$. This agrees with published data [10], although there is ongoing 
discussion on the precise optimal molar ratio of $\mathrm{Cu}^{2+} /$ LDL [11]. The results presented in Fig. 1 demonstrate that dialysis of LDL for 22 or $44 \mathrm{~h}$ in the presence of $0.01 \mathrm{mM}$ EDTA significantly decreased the lag phase $(P<0.001)$ compared with undialysed LDL. Omission of EDTA in the dialysis buffer did not result in a further decrease of the lag time observed after $44 \mathrm{~h}$ of dialysis. Neither the maximal rate of oxidation (Fig. 1) nor the maximal amount of conjugated dienes formed during oxidation was profoundly changed after dialysis. The maximal rate of oxidation was increased by about $25 \%$ after $44 \mathrm{~h}$ dialysis in the presence of EDTA. The reason for this increase is not clear at present.

As an estimation of the lipid peroxidation of polyunsaturated fatty acids during dialysis, we measured the level of MDA in LDL before and after dialysis. Freshly isolated LDL contained $1.04 \pm 0.35 \mathrm{nmol}$ MDA per mg protein. This value was virtually unchanged after $22 \mathrm{~h}$ of dial- ysis (1.34 $\pm 0.17 \mathrm{nmol} / \mathrm{mg})$. After dialysis for $44 \mathrm{~h}$ in the presence of EDTA the level of MDA tended to increase $(2.02 \pm 0.29)$, while after 44 $h$ in the absence of EDTA, MDA levels in LDL were significantly increased compared with the other dialysis conditions $(3.19 \pm 0.28 \mathrm{nmol} / \mathrm{mg}$ protein, $P<0.001$ ). The lipoperoxide levels in the same LDL preparations were $42 \pm 2,82 \pm$ $5,95 \pm 3$ and $372 \pm 68 \mathrm{nmol}$ per $\mathrm{mg}$ LDL protcin, respectively. Again the latter values are significantly increased compared with the other conditions $(P<0.001)$. Fig. 2 illustrates our findings on MDA and lipoperoxide contents of freshly isolated and dialysed LDL.

It must be kept in mind that not all lipophilic antioxidants present in plasma are exclusively present in LDL. Freshly isolated VLDL, LDL and HDL of our study subjects contained $13 \pm$ $6 \%, 45 \pm 5 \%$ and $30 \pm 7 \%$ of total plasma $\alpha$-tocopherol, respectively. The remaining $12 \pm$ $2 \%$ was located in the lipoprotein deficient plasma fraction of density $>1.21 \mathrm{~g} / \mathrm{ml}$. So both

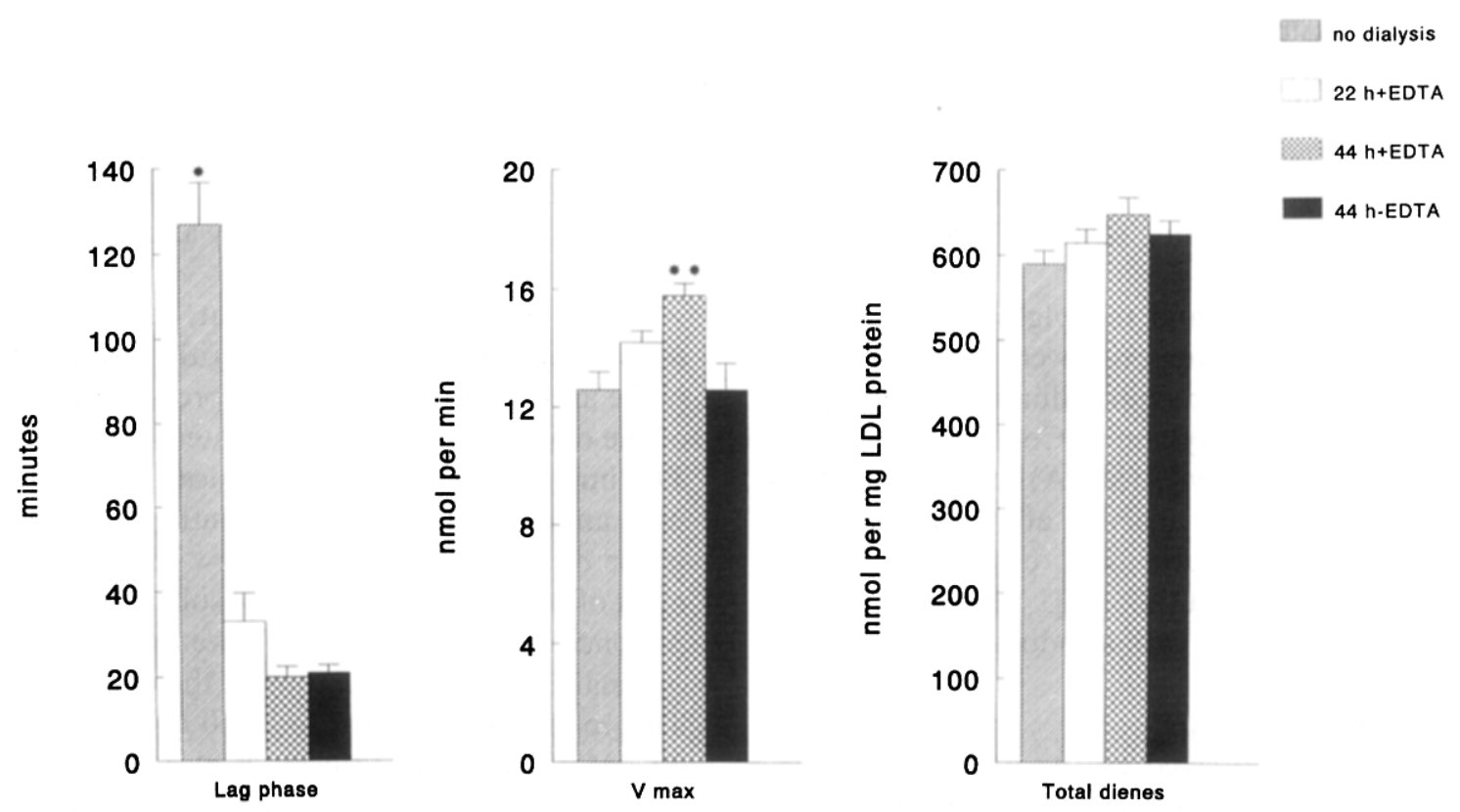

Fig. 1. Bar diagram showing lag phase before conjugated diene formation, the maximum oxidation rate and the maximal amount of dienes formed in copper-oxidised LDL which were not dialysed; dialysed for $22 \mathrm{~h}$ in the presence of EDTA (method A); dialysed for $44 \mathrm{~h}$ in the presence of EDTA (method B) or dialysed for $44 \mathrm{~h}$ in the absence of EDTA (method C). Values represent the mean \pm S.E.M. of LDL samples from 9 subjects. ${ }^{*}$ No dialysis significantly different from all dialysis groups, $P<0.001{ }^{* *}$ Significantly different from no dialysis, $P<0.01$. 

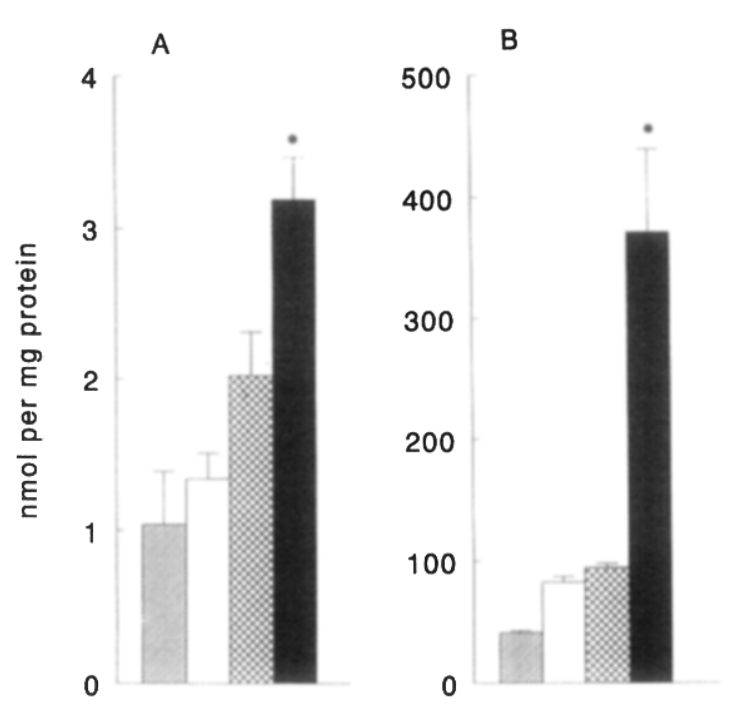

Fig. 2. The effect of different dialysis conditions on the concentration of malondialdehyde (A) and lipoperoxides (B) in LDL. LDL were not dialysed (hatched bars); dialysed for $22 \mathrm{~h}$ in the presence of EDTA (method A, open bars); dialysed for $44 \mathrm{~h}$ in the presence of EDTA (method B, double hatched bars) or dialysed for $44 \mathrm{~h}$ in the absence of EDTA (method C, closed bars). Values represent the mean \pm S.E.M. of LDL samples from 9 subjects. *Significantly different from no dialysis, $P<0.001$.

LDL and HDL are major carriers of $\alpha$-tocopherol in normolipidemic plasma. Expressed on a cholesterol basis LDL and HDL have $1.8 \pm 0.3$ and 3.3 $\pm 0.4 \mu \mathrm{g} \alpha$-tocopherol $/ \mu \mathrm{mol}$ cholesterol, respectively. It is conceivable that $\alpha$-tocopherol or other antioxidants from HDL may help to prevent LDL oxidation under in vivo conditions.

In summary, our data clearly show that dialysis of LDL results in a depletion of lipophilic antioxidants and in a decrease in the lag phase of copper-initiated oxidation of LDL particles. Antioxidants such as ubiquinol-10, not measured in the present study, could also be affected by dialysis. It can be concluded that dialysis may result in LDL particles that are not truly representative of freshly isolated lipoproteins. Future research should be directed towards the development of highly controlled, rapid procedures for LDL isolation. Our data show that it may be prudent not to submit LDL to prolonged dialysis. Recently Puhl et al. [11] have proposed gelfiltration as the standard procedure for removal of salts from LDL samples.

\section{Acknowledgements}

The authors would like to thank I.M. van Benschop, H. Meder and W.G.L. van Nielen for technical assistance.

\section{References}

[1] Witztum JL, Steinberg D. Role of oxidized low density lipoprotein in atherogenesis. J Clin Invest 1991;88:1785.

[2] Steinbrecher UP, Zhang H, Lougheed M. Role of oxidatively modified LDL in atherosclerosis. Free Rad Biol Med 1990;9:155.

[3] Schwartz CJ, Valente AJ, Sprague EA. A modern view of atherogenesis. Am J Cardiol 1993;71:9B.

[4] Esterbauer H, Wäg G, Puhl H. Lipid peroxidation and its role in atherosclerosis. Br Med Bull 1993;49:566.

[5] Esterbauer H, Gebicki J, Puhl H, Jürgens G. The role of lipid peroxidation and antioxidants in oxidative modification of LDL. Free Rad Biol Med 1992;13:341.

[6] Gutteridge JMC, Halliwell B. The measurement and mechanism of lipid peroxidation in biological systems. Trends Biochem Sci 1990;15:129.

[7] Cominacini L, Garbin U, Davoli A, Micciolo R, Bosello O, Gaviraghi G, Scuro LA, Pastorino AM. A simple test for predisposition to LDL oxidation based on the fluorescence development during copper-catalyzed oxidative modification. J I ipid Res 1991;32:349.

[8] Esterbauer H, Striegl G, Puhl H, Rotheneder M. Continous monitoring of in vitro oxidation of human low density lipoprotein. Free Rad Res Commun 1989;6:67.

[9] Esterbauer H, Jürgens G. Mechanistic and genetic aspects of susceptibility of LDL to oxidation. Curr Opin Lipidol 1993;4:114.

[10] Kleinveld HE, Hak-Lemmers HLM, Stalenhoef AFH, Demacker PNM. Improved measurement of low-densitylipoprotein susceptibility to copper-induced oxidation: application of a short procedure for isolating low-density lipoprotein. Clin Chem 1992;38:2066.

[11] Puhl H, Waeg G, Esterbauer H. In: Parker L. (ed). Methods in Enzymology, Vol. 233, Oxygen Radicals in Biological Systems, Part C. Academy Press, 1994;425.

[12] Reaven $P$, Parthasarathy $S$, Grasse BJ, Miller E, Almazan F, Mattson FH, Khoo JC, Steinberg D, Witztum JL. Feasibility of using an oleate-rich diet to reduce the susceptibility of low-density lipoprotein to oxidative modification in humans. Am J Clin Nutr 1991:54:701.

[13] Jialal I, Grundy SM. Effect of dietary supplementation with alpha-tocopherol on the oxidative modification of low density lipoprotein. J Lipid Res 1992;33:899.

[14] Princen HMG, Van Poppel G, Vogelezang C, Buytenhek R, Kok FJ. Supplementation with vitamin E but not beta-carotene in vivo protects low density lipoprotein from lipid peroxidation in vitro _. effect of cigarette smoking. Arteriosclerosis Thromb 1992;12:554. 
[15] Redgrave TG, Roberts DCK, West CE. Separation of plasma lipoproteins by density-gradient ultracentrifugation. Anal Biochem 1975;65:42.

[16] Markwell MAK, De Haas SM, Bieber LL, Tolbert NE. A modification of the Lowry procedure to simplify protein determination in membrane and lipoprotein samples. Anal Biochem 1978;87:206.

[17] Wong SHY, Knight JA, Hopfer SM, Zaharia O, Leach
CN Jr, Sunderman FW Jr. Lipoperoxides in plasma as measured by liquid chromatographic separation of malondialdehyde-thiobarbituric acid adduct. Clin Chem 1987;33:214.

[18] El-Saadani M, Esterbauer H, El-Sayed M, Goher M, Nassar AY, Juergens G. A spectrophotometric assay for lipid peroxides in serum lipoproteins using a commercially available reagent. J Lipid Res 1989;30:627. 